\title{
Inverted urothelial papilloma: A review of diagnostic piffalls and clinical management
}

\author{
Mary K. Sweeney; ${ }_{i}^{1}$ Soroush Rais-Bahrami, MD,2,3 Jennifer Gordetsky, MD \\ 'University of Alabama School of Medicine; ${ }^{2}$ Department of Radiology; ${ }^{3}$ Department of Urology; ${ }^{4}$ Department of Pathology; University of Alabama at Birmingham, Birmingham, AL, United States
}

Cite as: Can Urol Assoc J 2017;11 (1-2):66-9. hittp://dx.doi.org/10.5489/cuaj.4136

\section{Abstract}

Inverted urothelial papilloma (IUP) is a rare, non-invasive endophytic lesion that accounts for $1-2 \%$ of urothelial tumours. On cystoscopy, IUP appears as a pedunculated/papillary mass with a smooth surface. On microscopy, IUP has an endophytic growth pattern with the bulk of the tumour covered by a superficial layer of urothelium, which can be hyperplastic or attenuated. The cytology should be bland, with uniform, spindled cells arranged in anastomosing trabeculae and cords with peripheral palisading of basaloid cells. Exophytic papillae and mitotic activity should be absent or focal. Pseudoglandular spaces and squamous metaplasia may also be present. There are distinct molecular differences between IUP and urothelial carcinoma (UC). IUP rarely has mutations of FGFR3, homozygous loss of 9p21, or gain of chromosomes 3, 7, and 17, whereas these mutations are frequently seen in UC. In addition, IUP is much less likely to have TERT mutations compared to UC. Immunohistochemistry can also be helpful in distinguishing the two entities as IUP is typically negative for CK20 and has a low Ki-67 proliferation index. Positivity for p53 may be seen in a minority of IUP. IUP can recur and be seen in association with UC.

Distinguishing IUP from UC can be difficult due to the similarity between the two entities both on cystoscopy and histology, as up to $25 \%$ of UCs will also have inverted growth. Given the morphologic variants of IUP and UC, it is possible for a diagnostic error to occur, which can significantly impact patient management.

\section{Introduction}

Inverted urothelial papilloma (IUP) is a rare, non-invasive endophytic urothelial tumour that accounts for $1-2 \%$ of all urothelial neoplasms and can be found throughout the urinary tract. ${ }^{1-3}$ IUP was first described in 1927 by Paschkis as "polypoid adenomas," and then given its current name in 1963 by Potts and Hirst. ${ }^{4,5}$ Since first reported, there have been more than 1000 cases of IUP reported in the literature. ${ }^{6,7}$ IUP has been found in patients ranging from 20-89 years of age, with a mean age of 60 at the time of diagnosis and a male to female ratio of $6: 1 .^{8-10}$ Although IUPs can occur throughout the urinary tract, approximately $90 \%$ of lesions occur in the bladder, most commonly at the

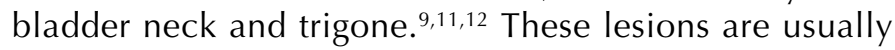
small $(<5 \mathrm{~cm})$; however, multifocality and larger lesions can occur, which can cause urinary outflow obstruction or ureteral obstruction. . $^{4,5}$

IUP grows in an endophytic pattern along the lamina propria to form nests and anastomosing trabeculae with cells in the centre of the nests often parallel to the basement membrane, creating a serpiginous configuration. ${ }^{8}$ Although considered a benign entity, IUP is associated with secondary development of urothelial carcinoma (UC), recurrence of disease, and presence of synchronous UC. ${ }^{9}$ It is crucial to recognize the diagnostic criteria and common morphological variants of IUP to distinguish it from UC or other reactive lesions like Von Brunn nests and cystitis cystica et glandularis. Herein, we review the clinical and pathological features of IUP with a focus on diagnostic pitfalls and management.

\section{Etiology}

It has been suggested that IUP growth occurs from hyperplasia of von Brunn's nests through a regenerative or reactive process. ${ }^{11}$ Others argue that IUP arises from reaction to inflammation, chronic infection, smoking, obstruction, or carcinogens. ${ }^{5,8,13,14}$ The underlying inflammatory process notion is reinforced by the similar appearance between IUP and cystitis cystica et glandularis. ${ }^{13}$ Some studies have suggested a correlation between human papillomavirus (HPV) infection and IUP due to positivity for p16. However, HPV has not been detected through immunohistochemistry or in situ hybridization (ISH), which is more specific for HPV infection in tissues. ${ }^{1,15}$

\section{Clinical presentation}

Painless gross hematuria is the most common presenting symptom in IUP, reported in up to $64 \%$ of patients. ${ }^{1,6,8,9,16}$ Patients may also have microscopic hematuria (6.8-15\%), 
dysuria $(8 \%)$, or other irritative lower urinary tract symptoms $(20 \%) .{ }^{1,3,6,8,9}$ Flank or low back pain is more common with upper urinary tract lesions, which can cause ureteral obstruction. ${ }^{3,5}$ Other, less common symptoms include pyuria, abdominal discomfort, and acute urinary retention. It is reported that $24 \%$ of patients have more than one presenting symptom and some patients are asymptomatic.9,12

\section{Imaging}

IUPs are frequently found incidentally on imaging studies or cystoscopy. ${ }^{3,4,7}$ In one study, $52.4 \%$ of IUPs of the prostatic urethra were found incidentally during the workup or treatment of prostate cancer or benign prostatic hyperplasia (BPH) ${ }^{16}$ On cystoscopy, IUP appears as a pedunculated mass or polypoid/papillary tumour with a smooth surface. ${ }^{11,17}$ Magnetic resonance imaging (MRI) typically shows a polypoid lesion with a non-papillary surface, a thin short stalk, and occasional cystic foci. ${ }^{10}$ IUP tends to be isointense on T1-weighted images and either isointense or slightly higher in intensity than the wall of the bladder on T2-weighted images. These lesions can also restrict diffusion on diffusion weighted MRI, similar to UC. On diffusion-weighted imaging (DWI), IUPs have very high signal intensity and low apparent diffusion coefficient values. On dynamic contrast-enhanced MRI, both IUP and UC strongly enhance in the early phase and have variable enhancement in the late phase representing variable washout kinetics.

\section{Biological behaviour}

The malignant potential of IUP has come into question due to the coexistence and subsequent development of UC recorded in the literature. Studies show that $2.5-10 \%$ of patients with IUP will eventually develop subsequent UC within 9-96 months following surgical resection on which the IUP was diagnosed. $3,5,7,11,16,18,19$ The location within the urinary tract may also contribute to malignant potential, as ureteral IUP has a threefold greater rate of subsequent development of UC than IUP of the bladder. ${ }^{7,19}$ However, given that $6 \%$ of IUPs are synchronously found with UC and the small size of ureteral biopsies, it is possible that the reported high rate of development of $U C$ in the ureter is a reflection of sampling bias and under-diagnosis of UC with inverted growth. ${ }^{9,12}$ Studies have shown rates of IUP recurrence from 1-7\%, which occur 5-30 months following resection. ${ }^{1,3-7,12,16,17}$ Furthermore, incomplete tumour resection contributes to a higher recurrence rate. ${ }^{7,9}$ However, as there are no reported cases of metastases arising from an IUP, it is believed that this lesion does not have malignant potential. $^{2}$

\section{Morphology and variants}

The diagnosis of IUP requires a urothelial lesion with inverted growth, covered by normal overlying urothelium (Fig.1A). The tumour grows in anastomosing cords and thin nests of cells growing down from the surface (Fig. 1B). Tumour cells should be uniform, with streaming and peripheral palisading of nuclei (Fig. 1C). The cellular layers should be of normal thickness and maintain polarity. ${ }^{2,8}$ Mitotic activity should be rare to absent. Microcyst formation and squamous metaplasia are also common ${ }^{20}$ (Fig, 1D). IUP should lack any significant exophytic component or fibrovascular cores and should be non-invasive, showing no desmoplasia, stromal inflammation, or involvement of the muscularis propria. ${ }^{17}$

IUPs are typically trabecular lesions composed of anastomosing cords of urothelial cells with nuclear streaming and peripheral palisading of basal nuclei. ${ }^{21} \mathrm{~A}$ glandular variant was proposed that had pseudoglandular and/or true glandular spaces with mucus-containing goblet cells. ${ }^{21,22}$ However, it is now recommended that the glandular variant of IUP should be considered florid cystitis cystica et glandularis. ${ }^{23}$

IUP has also been described with vacuolated or foamy cytoplasm present either focally or diffusely. ${ }^{8}$ These clear cells tend to be intermingled with the usual inverted papilloma cells. Since the finding of clear cells is unusual in IUP, it can be a pitfall for confusing the lesion for UC.

IUP with atypia is another proposed subtype; it has focal mild cytological atypia arising in an otherwise morphologically classic IUP. ${ }^{11}$ One study reported that IUPs with focal atypia do not tend to recur or be seen in association with

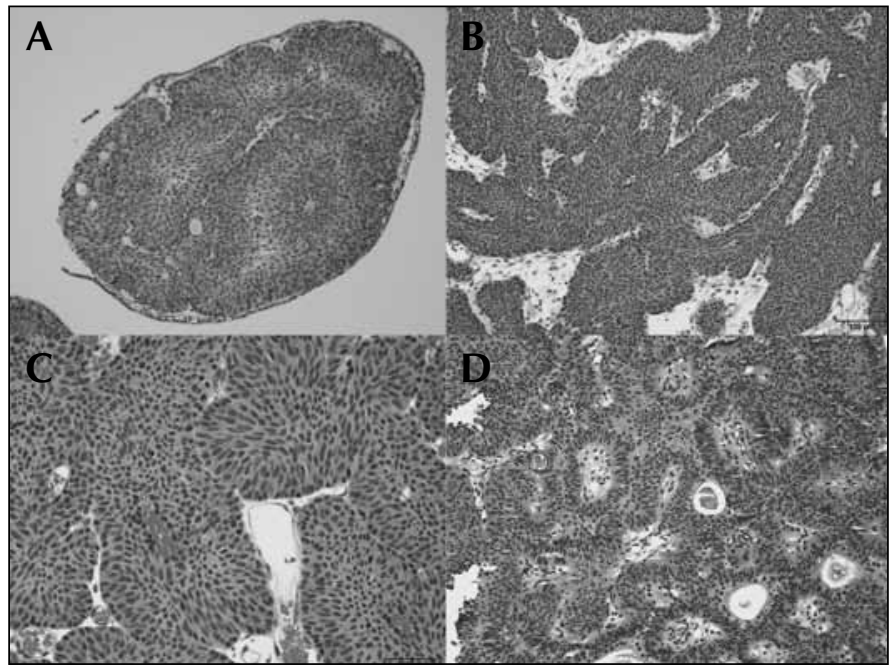

Fig. 1. (A) Low magnification hematoxylin and eosin (H\&E) of an inverted urothelial papilloma (IUP) covered by an attenuated layer of benign urothelium; (B) low magnification H\&E of an IUP showing anastomosing, thin trabeculae; (C) high magnification H\&E of an IUP showing spindled, bland cells, with peripheral palisading (no mitoses are present); (D) low magnification $\mathrm{H} \& \mathrm{E}$ showing cystic spaces within an IUP. 
Sweeney et al.

UC. ${ }^{11}$ However, many reported cases of "atypical IUP" in the literature are described with an exophytic papillary component and significant atypia and/or mitoses, which would best be considered UC with inverted growth. ${ }^{8,17}$

IUP with a focal papillary pattern has also been described. ${ }^{24}$ The papillary component in these cases should be focal and histologically similar to a urothelial papilloma with benign appearing urothelium of normal thickness and no cytologic atypia or mitoses. Any lesion morphologically similar to IUP, but with more than a focal papillary component, is best classified as a papillary urothelial neoplasm of low malignant potential (PUNLMP) or low-grade UC with inverted growth.

\section{Distinguishing IUP from UC}

Due to the overlapping morphology of IUP and UC, up to $27 \%$ of IUPs are incorrectly diagnosed as UC..$^{5,9}$ Discriminating IUP from a PUNLMP or low-grade UC with inverted growth can be difficult, especially given that up to $25 \%$ of UCs will have inverted growth. In addition, UC can have "IUP-like" patterns that show slender trabeculae and smooth nests. ${ }^{25}$ In Brimo et al, all 12 cases of invasive UC with an endophytic growth pattern contained areas within the tumour that were indistinguishable from IUP..$^{25}$ However, contrary to IUP, UC will have areas with invasive nests of variable sizes, with irregular borders and an inflammatory, desmoplastic stromal reaction. Cytologic atypia, necrosis, mitoses, nuclear pleomorphism, or irregular nuclear membranes should also be present. Lymphovascular invasion may also be seen. Many cases of UC will have an exophytic, papillary component, which is helpful in making the diagnosis. ${ }^{8,26}$ In addition, UC typically lacks cyst formation, which is a common finding in IUP. ${ }^{25,26}$ Perhaps most challenging is distinguishing an IUP from a PUNLMP with inverted growth. Although PUNLMPs will lack cytologic atypia, they will have thick-walled urothelium and an exophytic papillary component, which distinguishes them from IUP. ${ }^{27}$

Immunohistochemistry can be helpful in distinguishing IUP from UC. IUPs should have a low Ki-67 proliferation rate $(<1 \%)$ and typically negative staining for CK20. ${ }^{2,25,26,28}$ In one study, $27.8 \%$ of IUPs showed positivity for p53, making it unreliable in distinguishing IUP from UC. ${ }^{28} \mathrm{CK} 7$ positivity can be seen in IUP, especially in cases with vacuolated cells. ${ }^{17}$ Moreover, CK7 positivity and the absence of staining for PAS, PAS-D, and mucicarmine favours a diagnosis of IUP with vacuolated cells over the clear cell variant of UC. ${ }^{17}$

IUP has a molecular profile distinct from UC. UroVysion fluorescence in situ hybridization (FISH) has FDA approval for use in urine cytology for identifying urothelial lesions via detection of amplifications of chromosomes 3, 7, and 17 and deletion of $9 \mathrm{p} 21$. Studies have shown that up to $79 \%$ of UCs with inverted growth have abnormalities in these chromosomes, which is rare in IUP. $8,22,26$
When looking at non-invasive, low-grade papillary UCs that were negative for both $\mathrm{Ki}-67$ and CK20, 69.2\% were distinguished from IUP through positive detection on UroVysion FISH. ${ }^{26,28}$ Eiber et al compared 62 IUPs to 23 UCs with inverted growth. IUP and UC showed statistically significant differences in Fibroblast growth factor receptor 3 (FGFR3) mutations, Ki-67 proliferation index $(\mathrm{p}<0.001$ each), and $9 q$ loss of heterozygosity. ${ }^{29}$

In another study, next-generation sequencing revealed HRAS point mutations in three of five $(60 \%)$ IUPs. This mutation is rarely seen in UC. ${ }^{15}$

Telomere shortening is another useful biomarker in distinguishing IUP from UC. Williamson et al found a statistically significant reduction in the relative telomere length (RTL) in UC with inverted growth compared to those found in IUP. ${ }^{30}$ There were no statistically significant differences in the RTL between normal urothelium, cystitis glandularis, and IUP.

Finally, IUP is often diploid, has a low rate of loss of heterozygosity, and is less likely to have TERT mutations compared to UC. . $^{18,22}$

\section{Clinical management}

A conservative approach via transurethral resection is often appropriate for lower urinary tract lesions, as IUP of the bladder is a non-invasive lesion. ${ }^{9}$ However, upper urinary tract lesions may be too large to be managed by ureteroscopy and may require a percutaneous approach through endoscopic resection, partial ureterectomy, or nephrectomy. ${ }^{11}$

Rarely, IUP can be multifocal, recur, and be associated with UC. Picozzi et al reported synchronous UC (1.4\%) and subsequent $U C$ of the bladder (1.1\%) within 45 months of surgery. ${ }^{9}$ As such, most agree that patients with a diagnosis of IUP require continued surveillance. ${ }^{7}$ Studies have recommended frequent cystoscopy with urine cytology for at least two years following diagnosis of IUP, with some suggesting indefinite annual exams thereafter. ${ }^{2,3,6,11}$ Other authors have stated that rigorous, long-term surveillance protocols are unnecessary in cases with a solitary lesion, complete resection, and no concurrent $U C$ findings. ${ }^{4,5,7,12,22}$ A moderate approach in cases without a history of UC would include frequent cystoscopy for the first year, followed by further examinations based only on recurrent symptoms. ${ }^{4}$

\section{Conclusion}

IUP is a benign, uncommon tumour that can occur throughout the urinary tract, with no recognized ability for malignant transformation. Morphology is critical in distinguishing IUP from UC with inverted growth. Immunohistochemistry and molecular studies can also be helpful in differentiating the two entities. Although rare, this lesion may be multifocal, 
recur, and be associated with subsequent UC formation. As such, clinical followup with cystoscopy is recommended.

Competing interests: The authors report no competing personal or financial interests.

This paper has been peer-reviewed.

\section{References}

1. Alexander RE, Davidson DD, Lopez-Beltran A, et al. Human papillomavirus is not an etiologic agent of urothelial inverted papillomas. Am J Surg Pathol 2013;37:1223-8. https://doi.org/10.1097/ PAS.0b013e3182863fcl

2. Broussard JN, Tan PH, Epstein JI, et al. Atypia in inverted urothelial papillomas: Pathology and prognostic significance. Hum Pathol 2004;35:1499-1504. https://doi.org/10.1016/i.humpath.2004.09.010

3. Darras J, Inderadiaja N, Vossaert P. Synchronousinverted papilloma of bladder and renal pelvis. Urology 2005;65:798e25-798e28.

4. Patel P, Reikie BA, Maxwell JP. Long-term clinical outcome of inverted urothelial papilloma including cases with focal papillary pattern: Is continuous surveillance necessary? Urology 2013;82:857-60. https://doi.org/10.1016/i.urology.2013.06.040

5. Wities JA, Balken MR, Kaa CA. The prognostic value of a primary inverted papilloma of the urinary tract. J Urol 1997;158:1500-5. https://doi.org/10.1016/S0022-5347(01)64253-8

6. Asano K, Miki J, Maeda S, et al. Clinical studies on inverted papilloma of the urinary tract: Report of 48 cases and review of the literature. Urology 2003;170:1209-12. https://doi.org/10.1097/01. ju.0000085342.15918.d7

7. $\mathrm{Ho} \mathrm{H}_{\mathrm{H}}$, Chen YD, Tan PH, et al. Inverted papilloma of urinary bladder: Is long-term cystoscopic surveitlance needed? A single centre's experience. Urology 2006;68:333-6. https://doi.org/10.1016/i. urology.2006.03.014

8. Guo A, Liu A, Teng X. The pathology of urinary bladder lesions with an inverted growth pattern. Chin $J$ Cancer Res 2016;28:107-21.

9. Picozzi $S$, Casellato $S$, Bozzini $G$, et al. Inverted papilloma of the bladder: A review and an analysis of the recent literature of 365 patients. Urol Oncol 2013;31:1584-90. https://doi.org/10.1016/i. urolonc.2012.03.009

10. Takeuchi M, Sasaguri K, Naiki T, et al. MRI findings of inverted urothelial papilloma of the bladder. AJR Am J Roentgenol 2015;205:311-6. https://doi.org/10.2214/AJR.14.13879

11. Brown AL, Cohen RJ. Inverted papilloma of the urinary tract. BJU Int 2010;107:24-6. https://doi.org/10.1111/i.1464-410X.2011.10046.x

12. Sung MT, MacLennan GT, Lopez-Beltran A, et al. Natural history of urothelial inverted papilloma. Cancer 2006; 107:2622-7. https://doi.org/10.1002/cncr.22311

13. Chiura AN, Wirtschafter A, Bagley DH. Upper urinary tract inverted papillomas. Urology 1998;52:514-6. https://doi.org/10.1016/S0090-4295(98)00225-8

14. Spevack L, Herschorn S, Srigley J. Inverted papilloma of the upper urinary tract. J Urol 1995; 153:1202-4. https://doi.org/10.1016/S0022-5347(01)67552-9
15. McDaniel AS, Zhai Y, Cho KR, et al. HRAS mutations are frequent in inverted urothelial neoplasms. Hum Pathol 2015;45:1957-65. https://doi.org/10.1016/i.humpath.2014.06.003

16. Fine SW, Chan TY, Epstein II. Inverted papillomas of the prostatic urethra. Am J Surg Pathol 2006;30:9759. https://doi.org/10.1097/00000478-200608000-00007

17. Fine SW, Epstein II. Inverted urothelial papillomas with foamy or vacuolated cytoplasm. Hum Pathol 2006;37:1577-82. https://doi.org/10.1016/i.humpath.2006.05.014

18. Cheville JC, Wu K, Sebo TJ et al. Inverted urothelial papilloma: Is ploidy, MIB-1 proliferative activity, or p53 protein accumulation predictive of urothelial carcinoma? Cancer 2000;88:632-6. https://doi.org/10.1002/(SICI) 1097-0142(20000201)88:3<632::AID-CNCR21>3.0.C0;2-F

19. Kimura $\mathrm{G}$, Tsuboi $\mathrm{N}$, Nakajima $\mathrm{H}$, et al. Inverted papilloma of the ureter with malignant transformation. $\mathrm{A}$ case report and review of the literature. The importance of the recognition of the inverted papillary tumour of the ureter. Urol Int 1987;42:30-6. https://doi.org/10.1159/000281846

20. Henderson DW, Allen PW, Bourne AJ. Inverted urinary papilloma: Report of 5 cases and review of the literature. Virchows Arch A Pathol Anat Histol 1975;366:177-86. https://doi.org/10.1007/BF00427408

21. Kunze E, Schauer A, Schmitt M. Histology and histogenesis of 2 different types of inverted urothelial papillomas. Cancer 1983;51:348-58. https://doi.org/10.1002/1097-0142(19830115)51:2<348::AlDCNCR2820510231>3.0.C0;2-0

22. Hodges KB, Lopez-Beltran A, Maclennan GT, et al. Urothelial lesions with inverted growth patterns: Histogenesis, molecular genetic findings, differential diagnosis, and clinical management. BJU Int 2010;107:532-7. https://doi.org/10.1111/i.1464-410X.2010.09853.x

23. Matz LR, Wishart VA, Goodman MA. Inverted urothelial papilloma. Pathology 1974;6:37-44. https://doi.org/10.3109/00313027409077154

24. Albores-Saavedra J, Chable-Montero F, Hernández-Rodríguez OX, et al. Inverted urothelial papilloma of the urinary bladder with focal papillary pattern: A previously undescribed feature. Ann Diagn Pathol 2009;13:158-61. https://doi.org/10.1016/i.anndiagpath.2009.02.009

25. Brimo F, Dauphin-Pierre $S$, Aprikian A. Inverted urothelial carcinoma: A series of 12 cases with a wide morphologic spectrum overlapping with the large nested variant. Hum Pathol 2015;46:1506-13. https://doi.org/10.1016/i.humpath.2015.06.010

26. Jones TD, Zhang S, Lopez-Beltran, et al. Urothelial carcinoma with an inverted growth pattern can be distinguished from inverted papilloma by fluorescence in situ hybridization, immunohistochemistry, and morphologic analysis. Am J Surg Pathol 2007;31:1861-7. htrps://doi.org/10.1097/PAS.0b013e318060cb9d

27. Maxwell JP, Wang C, Wiebe N, et al. Long-term outcome of primary papillary urothelial neoplasm of low malignant potential (PUNLMP) including PUNLMP with inverted growth. Diagn Pathol 2015;10:3. https://doi.org/10.1186/s13000-015-0234-z

28. Sun JJ, Wu Y, Lu YM, et al. Immunohistochemistry and fluorescence in situ hybridization can inform the differential diagnosis of low-grade non-invasive urothelial carcinoma with an inverted growth pattern and inverted urothelial papilloma. PLOS One 2015;10:1-13. https://doi.org/10.1371//ournal. pone. 0133530

29. Eiber $\mathrm{M}$, van Oers $\mathrm{JM}$, Zwarthoff $\mathrm{EC}$, et al. Low frequency of molecular changes and tumour recurrence in inverted papillomas of the urinary tract. Am J Surg Pathol 2007;6:938-46. https://doi.org/10.1097/01.pas.0000249448.13466.75

30. Williamson SR, Zhang S, Lopez-Beltran A, et al. Telomere shortening distinguishes inverted urothelial neoplasms. Histopathology 2013;62:595-601. hitps://doi.org/10.1111/his.12030

Correspondence: Dr. Jennifer Gordetsky, Department of Pathology and Urology, University of Alabama at Birmingham, Birmingham, AL, United States; igordetsky@uabmc.edu 